\title{
Food and Water Consumption Original Result Unit
}

National Cancer Institute

\section{Source}

National Cancer Institute. Food and Water Consumption Original Result Unit. NCI

Thesaurus. Code C119834.

The unit of measure for the result of the food and water consumption assessment as

originally received or collected. 